\title{
A Fourfold Typology of Living Labs: an Empirical Investigation amongst the ENoLL Community
}

\author{
Dimitri Schuurman ${ }^{1}$, Dominik Mahr ${ }^{2}$, Lieven De Marez ${ }^{1}$, Pieter Ballon ${ }^{3}$ \\ ${ }^{1}$ iMinds-MICT-Ghent University, Korte Meer 7-9-11, 9000 Ghent, Belgium, \\ \{dimitri.schuurman,lieven.demarez\}@ugent.be \\ ${ }^{2}$ Maastricht University, Minderbroedersberg 4-6, 6211 LK Maastricht, The Netherlands, \\ d.mahr@maastrichtuniversity.nl \\ ${ }^{3}$ iMinds-SMIT-VUB, Pleinlaan 9, 1050 Brussels, Belgium, pieter.ballon@vub.ac.be
}

\begin{abstract}
Living Labs can be seen as a means to structure user involvement in innovation processes. However, in this rather young research domain, there is no consensus yet regarding supporting theories and frameworks. This has resulted in a wide variety of projects and approaches being called 'Living Labs', which leaves a clear conceptualization and definition a task in progress. Within this research paper we propose a fourfold categorization of Living Labs based on a literature review and validated by an empirical investigation of the characteristics of 64 ICT Living Labs from the European Network of Living Labs (ENoLL). The four types are Living Labs for collaboration and knowledge support activities, original 'American' Living Labs, Living Labs as extension to testbeds and Living Labs that support context research and co-creation with users.
\end{abstract}

\section{Keywords}

Living Labs, Open innovation, User involvement, Co-creation

\section{Introduction}

Living Labs can be seen as a rather new research area with only a limited amount of theories already put forwards for understanding this concept [Ståhlbröst \& Bergvall-Kåreborn, 2008]. The lack of agreement regarding the supporting theories [Eriksson et al., 2005]; [Schaffers \& Kulkki, 2007] has induced a proliferation of papers and articles on Living Labs and led to a variety of approaches and projects carried out under the Living Labs-umbrella [Shamsi, 2008].

In Europe, the Living Lab-movement gained momentum through its support by EU-policy, as it is tightly linked to the 'Strengthening innovation and investment in ICT research'-pillar of i2010, the EU policy framework for the information society and media [Peltomäki, 2008]. Within this context, several international organizations representing industrial ICT Living Lab-initiatives were founded of which the European Network of Living Labs (ENoLL) is the most well-known. ENoLL was founded in November 2006 under the guidance of the Finnish European Presidency. It is the international federation of Living Labs that have been benchmarked - both in Europe and beyond - and its headquarter is located in Brussels. Next to a variety of European countries, such as Belgium, Finland, Germany, Italy, Spain and UK, other countries, as Brazil, Canada and the United States are involved with the network [ENoLL, 2012]. It is built up through the partnership of different stakeholders, like public bodies (e.g. municipalities, universities and research institutes), different business companies (predominantly SMEs) and users [Santoro \& Conte, 2009]. Over the past few years, the network has constantly grown in so-called waves and up to now six waves have been launched and a total of 320 Living Labs were accepted [ENoLL, 2012]. Meanwhile, the number of Living Labs is constantly growing. They represent a highly interesting topic for all parties being involved with $R \& D$, marketing and innovation, as they are 
likely to give rise to "a paradigm shift for jobs, growth and competitiveness" [Prime Minister's Office, 2006a]. Therefore, the EU Commission allocated 40 Million of Euros, in order to promote the development of the ENoLL [Prime Minister's Office, 2006b]. The overall aim of the network is to support the creation of a dynamic innovation system throughout Europe. Essentially, the ENoLL tries to foster "co-creative, human-centric and user-driven research, development and innovation in order to better cater for people's needs" [ENoLL, 2012]. By linking separate Living Labs around the globe, the network enables the participating players to share their knowledge and learn from each other. Given this international context, the ENoLL facilitates the testing of products and services in different cultural environments. This is of great importance, as previous research has proven that cultural differences often influence the take-off or acceptance of innovations [Steenkamp, Hofstede \& Wedel, 1999].

However, this has also led to a large variety of initiatives carrying the Living Labs-label in order to get European funding and applying to become a member of ENoLL. The number of 320 Living Labs also needs to be revised as our research showed that a lot of these initiatives are no longer active (cf. infra). Therefore, on a theoretical as well as on a practical level, a further delineation of the Living Lab-concept remains a task in progress. In this paper, we will add to the current literature by constructing a typology of Living Labs based on a literature review and empirically validating this typology by means of an analysis of 64 active ICT Living Labs from ENoLL.

\section{Relation to Existing Theories and Work}

\subsection{Living Lab characteristics}

The most cited work positioning Living Labs amongst other Test and Experimentation Platforms (TEPs) remains a multiple case study analysis by Ballon et al. [2007]. They identified six TEPs (Prototyping, Field Trials, Testbeds, Societal Pilots, Market Pilots and Living Labs) which they found differing on three relevant dimensions: technological readiness (low to high maturity), research focus (testing versus design) and openness (in-house activities to open platforms). For Living Labs, the commercial maturity of the innovation in development is lower than is the case within societal and market pilots. The focus is more on the design of the innovation and less on the testing compared to Field Trials and Testbeds. One major conclusion stated that Living Labs have a unique role between early prototypes and fully developed products. Living Labs are eventually defined as 'an experimentation environment in which technology is given shape in real life contexts and in which (end) users are considered 'co-producers' [Ballon et al., 2007].

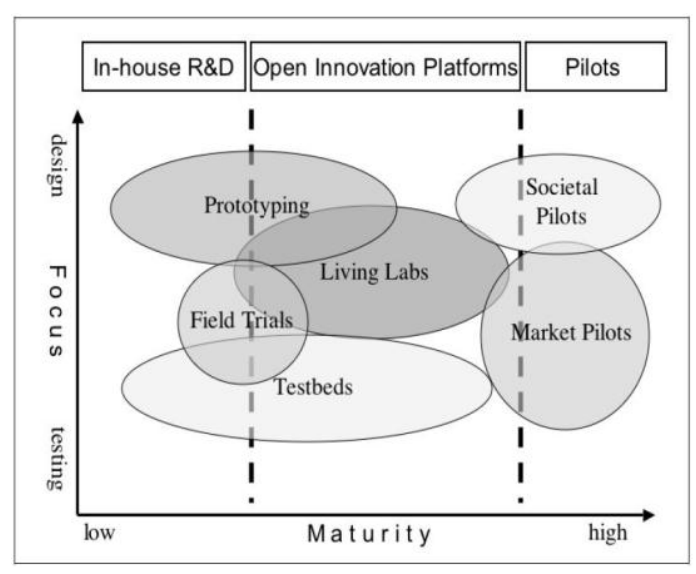

Figure 1. Classification of TEPs [Ballon et al., 2007] 
However, as can be witnessed from the well-known figure depicting the different TEPs for the three given dimensions, there is quite some overlap between these six TEPs. This suggests that the boundaries between these different approaches are in practice often fuzzy and that a lot of elements within these approaches are quite similar.

A second main attempt with the intention to enrich theory-building regarding Living Labs can be found in Følstad [2008]. He conducted a wide literature review of ICT Living Labs, also the focus of our own empirical study, and abstracted the main elements from the case studies. $\mathrm{He}$ eventually identified nine distinct Living Lab-characteristics. The first five are characterizing purposes that deal with the Living Lab contributions to the innovation development process: 1 . Investigate the usage context, 2. Discovery of unexpected usage and new service opportunities, 3. Co-creation with the users, 4. Evaluation or validation of new ICT solutions by users and 5. Technical testing of the innovation. Two characterizing purposes have to do with the Living Labcontext: 6. Familiar usage context and 7. Real-world context. The final two elements consist of characteristics of Living Lab-studies: 8. Medium- or long-term research and 9. Large scale research. Four purposes were found to be common for the studied Living Lab-approaches: discovery, evaluation, familiar context and medium- or long-term. The other characteristics were regarded as diverging perspectives on Living Labs. The fact that more than half of the nine elements are not present in the majority of the analysed cases might also be a further proof of the fuzziness and overlap with other innovation methodologies.

\subsection{Living Lab-typologies from literature}

Besides some early mentions of 'Living Labs' in the context of biology and medicine, the term was first used at MIT in its present connotation to describe a laboratory environment with all facilities of a regular home, optimized for multi-day or multi-week observational studies of single individuals and constructed to resemble a 'real' home as closely as possible [Intille et al., 2005]. Volunteer research participants inhabited these 'living laboratories' where the routine activities and interactions of everyday home life can be observed, recorded for later analysis, and experimentally manipulated [Eriksson et al., 2005]. A fitting example of this kind of Living Labs can be found in Markopoulos \& Rauterberger [2000] who confront Living Labs with so-called 'smart home' type projects. Whereas the latter type of projects acts as a showcase of an integrated vision of the 'home of the future', they define their Living Lab as a testing facility with as primary research goal to focus on how ubiquitous computing technology can be designed to fit the daily lives of the Living Lab inhabitants. Summarizing, this definition sees the Living Labconcept merely as a research facility that tries to overcome the artificial lab-context and is referred to as the American vision on Living Labs [Schuurman et al., 2011].

A major divergence of the 'European' Living Labs from this American notion is that the user is now studied in his or her everyday habitat. However, there are set-ups and occurences within this 'European' notion. Følstad [2008] distinguishes two: Living Labs supporting context research and co-creation and Living Labs as extensions to testbeds. Characteristics of this first type of Living Labs include co-creation of new ICT-services and collection of information on the usage context with sometimes ethnographic approaches to enable data collection [Pierson \& Lievens, 2005]. These Living Labs can focus on the early development phases of needs analysis and (iterative) design, where, based on an identified problem, a solution is developed in close interaction with end-users [Thiesen Winthereik et al., 2009]. However, other Living Labs of this type are more evaluative in nature and focus on the iterative finetuning of innovative products or services, tapping into the innovative capacity of test-users [Schuurman \& De Marez, 2012].

The testbed-like type of Living Labs can be found in the work of e.g. Ponce de Leon [2006] and Zhong et al. [2006]. They use the term to describe testbeds (controlled network environments for test and validation) for ICT services. Følstad [2008] makes the observation that the opportunity to conduct real-world validation studies of testbed applications seems to be an important 
motivation for many of the Living Labs belonging to ENoLL, something which is also apparent in the work of Ballon et al. [2007] (cf. supra).

Besides these three general categories of Living Labs, a fourth type can also be distinguished in the literature. This final type is more focussed towards multi-stakeholder collaboration and knowledge sharing, with less emphasis on developing and testing of new technologies or on deep end-user involvement. Buitendag et al. [2012] define collaboration and knowledge support activities as cardinal to a successful Living Lab. Coetzee et al. [2012] point out to this difference between examples of this type of Living Labs in South Africa and the 'European LLs'. A main distinguishing element is the emphasis on collaboration with communities, specifically rural communities, in contrast to European LLs' co-creation with 'users' who are mostly located in urban areas. Whereas European Living Labs operate more on a project-basis, these Living Labs are predominantly long-term and involve prolonged engagement with communities.

Leminen et al. [2012] take another approach, as they propose to differentiate Living Labs based on which actor drives their activities: utilizer-driven, enabler-driven, provider-driven and userdriven Living Labs. We will now briefly review these four types of Living Labs.

\section{Utilizer-driven Living Labs}

As utilizers are companies that launch Living Labs to develop their businesses, the focus is on developing and testing new products and services. These utilizers use Living Labs as a strategic tool to collect data on test-users of their products or services, organizing most Living Lab activities around themselves granting them a central position in the network. Because these utilizers mostly strive for rapid results, utilizer-driven living labs are often short lived or projectbased. This type of Living Labs resembles living labs supporting context research and cocreation with users.

\section{Enabler-driven Living Labs}

Enablers of Living Labs can be various public sector actors, non-governmental organizations, or financiers, such as towns, municipalities, or development organizations. Enabler-driven Living Labs are typically public-sector projects that pursue some kind of social innovation or societal improvements. Participation of private companies in this type of Living Labs tends to be low, suggesting that the potential business benefits are not clear to utilizer firms. A main aspect is the creation and sharing of knowledge and information across the network through the actors in the Living Lab. Typically, this type of Living Labs last significantly longer compared to utilizerdriven living labs. Looking back at our literature review, we can conclude that these enablerdriven Living Labs are very similar to the Living Labs for collaboration and knowledge sharing.

\section{Provider-driven Living Labs}

Providers can be public organizations as well as private companies that enter into Living Labs to co-develop new products, services and solutions to their business or industry needs. They provide the network with their product or service portfolio. Provider-driven Living Labs aim at promoting research and theory development, augmenting knowledge creation, and finding solutions to specific problems. Much of the innovation is about generating useful knowledge and information for everyone in the network. Provider-driven Living Labs focus on improving users' everyday life in a way that allows for all participants in the network benefit from the resulted innovation. Some provider-driven living labs are built around a single project, whereas others have succeeded in establishing themselves as longer-lived innovation platforms. An example of the latter case is companies (utilizers) testing and fine-tuning innovative services or products on a technical infrastructure hosted by the provider. In the light of our literature review, providerdriven Living Labs can thus refer to the original American notion of Living Labs, where a lab infrastructure is provided to study end-users in an environment resembling their everyday life. Testbed-like Living Labs can also be seen as provider-driven, as the technical testbed infrastructure is also provided to test and develop innovative ICT-services, although the actual innovation projects can be seen as utilizer-driven. Where Leminen et al. [2012] argue that Living 
Labs are usually either utilizer-driven or provider-driven because both emphasize efficiency with regards to the firms' investments, our observation complements this statement, as Living Labs can be provider- and ultilizer-driven, depending on the focus of the analysis (case-based or infrastructure-based).

\section{User-driven Living Labs}

User-driven Living Labs are established by user communities and focus on solving users' everyday-life problems. They typically build upon a significant problem or a specific community of interest. Value is (co-)created mainly for the user community, but the companies and society in general also benefit indirectly. User-driven living labs are long lived, because they are built around the user community. When looking at our literature review, this kind of 'bottom-up Living Labs' could not be found in the presented Living Lab definitions. This can be explained by the fact that Leminen et al. [2012] found that these kinds of Living Labs are quite uncommon to date. We believe that this type of Living Lab might be an outcome of for example an enablerdriven Living Lab where a community of end-users is stimulated to participate and conduct innovative activities themselves, but that it is hard to establish a bottom-up user-driven Living Lab 'from scratch'.

The table below summarizes the main findings from our literature review in a fourfold typology of Living Labs. For each type, two examples from literature are provided, together with a short description of their characteristics and a classification in the light of the types of Leminen et al. [2012].

\begin{tabular}{|c|c|c|c|}
\hline $\begin{array}{lr}\text { Living Labs } & \text { for } \\
\text { collaboration } & \text { and } \\
\text { knowledge } & \text { support } \\
\text { activities } & \end{array}$ & $\begin{array}{l}\text { Original } \\
\text { Living Labs }\end{array}$ & $\begin{array}{l}\text { Living Labs as } \\
\text { extension to testbeds }\end{array}$ & $\begin{array}{l}\text { Living Labs supporting } \\
\text { context research and } \\
\text { co-creation }\end{array}$ \\
\hline $\begin{array}{l}\text { Coetzee et al. (2012), } \\
\text { Buitendag et al. (2012) }\end{array}$ & $\begin{array}{l}\text { Markopoulos \& } \\
\text { Rauterberg (2000), Hess } \\
\text { \& Ogonowski (2009) }\end{array}$ & $\begin{array}{l}\text { Ponce de Leon et al. } \\
\text { (2006), Zhong et al. } \\
\text { (2006) }\end{array}$ & $\begin{array}{l}\text { Thiesen Winthereik et } \\
\text { al. (2009), Schuurman } \\
\text { \& De Marez (2012) }\end{array}$ \\
\hline $\begin{array}{l}\text { Multi-stakeholder } \\
\text { collaboration, focus on } \\
\text { collaborative platforms, } \\
\text { knowledge sharing and } \\
\text { community } \\
\text { development }\end{array}$ & $\begin{array}{l}\text { Laboratory made to } \\
\text { resemble the real-world, } \\
\text { smaller scale, data } \\
\text { capturing, can also be in- } \\
\text { home research on a small } \\
\text { scale focusing on } \\
\text { ethnographic methods }\end{array}$ & $\begin{array}{l}\text { Environments within } \\
\text { which users and } \\
\text { stakeholders } \\
\text { collaborate in the } \\
\begin{array}{l}\text { creation } \\
\text { validation of } \\
\text { services }\end{array}\end{array}$ & $\begin{array}{l}\text { Environments aimed to } \\
\text { support innovation } \\
\text { processes focusing on } \\
\text { the early development } \\
\text { phases of needs } \\
\text { analysis and early } \\
\text { design }\end{array}$ \\
\hline Enabler-driven & Provider-driven & $\begin{array}{l}\text { Provider-driven } \\
\text { infrastructure with } \\
\text { Utilizer-driven } \\
\text { projects }\end{array}$ & Utilizer-driven \\
\hline
\end{tabular}

Table 1: Different types of Living Labs

When confronting these four types from literature with the work of the first section in this review, the first type, Living Labs for collaboration and knowledge sharing, is less in line with the focus on testing and experimentation and is also less tailored towards thorough user involvement. This type of Living Labs thus seems to be divergent from this original notion of Living Labs. 


\section{Research approach}

In order to validate the fourfold typology we developed based on our literature review, we conducted an empirical assessment of the given framework. The unit of analysis are ICT Living Labs registered at the European Network of Living Labs, which was discussed in more detail in the previous section. Cooperation with the network enabled us to access the non-public registration documents and facilitated contact with a key responsible at each Living Lab, resulting in a unique data set. The data collection took place in two steps. The first step - "Living Lab Characteristics" - encompassed a quantitative assessment of Living Labs, based on the nine characteristics established in Følstad's [2008] review. Two experts, one part of and one distant to the author team, reviewed the publicly available material and the internal registration documents, and independently assessed the characteristics of all 64 Living Labs on scale from 1 (low) to 4 (high). The coding scheme can be found in annex. The second step augmented the data from the first step with in-depth interviews with key informants at the Living Labs. The analysis of the data followed two steps which paralleled the data collection. Step 1 ("Living Labs characteristics") encompassed the assessment of 64 Living Labs. The coding of the experts showed high reliability (Krippendorff $\alpha>.8$ ), except for co-creation and technical testing $(\alpha>.6)$. Disagreements were re-examined and dissolved. To uncover higher-order characteristics among the nine Living Labs characteristics, and cluster the Living Labs, we conducted K-means clustering with an ordinal scaling level in IBM SPSS Statistics 19 for a four cluster solution, similar to our fourfold typology. In order to elaborate upon the data, the interviews were used as a means to clarify and add to the understanding.

\section{Findings}

For the description of the Living Lab clusters, we used the cluster means of the original nine characteristics. All data can be found in table 2. Within Cluster 1, the highest means for all user contribution items can be found. The same goes for familiarity and real-world context, but the size and duration are relatively small. This implies intense user involvement and co-creation with a small set of users for a shorter period of time. In contrast, cluster 2 consists of Living Labs with the lowest user contribution and lowest degree of realism in terms of familiarity and real-world context. Size and duration are however significantly higher. Cluster 3 shows the second highest means for user contribution and for familiar and real-world context. This cluster has the highest values for duration and size, indicating a long-term involvement of a large group of users. Cluster 4 consists of Living Labs in laboratory conditions that however resemble familiar usage contexts with a rather low user contribution. User samples are rather small, but the duration of the Living Labs has the second highest value of all four clusters.

In the light of our fourfold typology, we can elaborate upon the discovered clusters. Cluster 1 clearly resembles the 'European' notion of Living Labs with a focus on co-creation of products and services with users based on real-world experiences. Testing is also an important aspect amongst these Living Labs. This observation, together with the small scale and the shorter duration point to Living Labs that are rather utilizer-driven and more project-based. With 19 out of the 64 Living Labs being classified in this cluster, this is the second biggest population within our sample. As an example we can mention the LeYLab Living Lab (http://www.leylab.be) where a small sample of homes (around 100) were equipped with a fibre-to-the-home infrastructure and some of them with testing devices such as tablets or media PCs connected to their TVs. Some Living Lab cases were initiated during the running time of the project (2 years) 
where small groups of test-users co-created and validated innovative applications on the Living Lab-infrastructure. Cluster 2 clearly stands out from the other three. With only seven Living Labs, it is by far the smallest. With the low user involvement and the low emphasis on testing, this cluster resembles the Living Labs for collaboration and knowledge sharing. An example of this type of Living Lab is Siyakhula Living Lab in South-Africa, a collaborative project aimed at enhancing and developing rural areas by providing them with ICT-infrastructure (http://siyakhulall.org/). This kind of Living Labs is predominantly enabler-driven.

\begin{tabular}{|c|c|c|c|c|c|}
\hline $\begin{array}{l}\text { K-Means } \\
\text { Clustering } \\
\text { Dimensions }\end{array}$ & $\begin{array}{l}\text { Characteristics } \\
\text { according to Følstad }\end{array}$ & $\begin{array}{l}\text { Cluster 1: } \\
\text { Small scale } \\
\& \quad \text { real- } \\
\text { world user } \\
\text { co-creation }\end{array}$ & $\begin{array}{l}\text { Cluster 2: } \\
\text { Long term } \\
\text { knowledge } \\
\text { sharing \& } \\
\text { collaboration }\end{array}$ & $\begin{array}{l}\text { Cluster 3: } \\
\text { Large scale \& } \\
\text { long term with } \\
\text { moderate user } \\
\text { involvement }\end{array}$ & $\begin{array}{l}\text { Cluster } 4: \\
\text { Long term } \\
\text { user studies in } \\
\text { lab context on } \\
\text { a small scale }\end{array}$ \\
\hline \multirow{3}{*}{ User Contribution } & Unexpected use & 2.79 & 1.71 & 2.05 & 1.88 \\
\hline & User co-creation & 3.37 & 1.86 & 2.52 & 1.94 \\
\hline & User validation & 3.53 & 1.86 & 2.48 & 2.12 \\
\hline \multirow{7}{*}{ Contextual Reality } & Familiar context & 3.58 & 1.71 & 3.38 & 2.59 \\
\hline & Real-world context & 3.21 & 1.14 & 2.62 & 1.88 \\
\hline & Large user sample & 1.28 & 2.17 & 3.71 & 1.88 \\
\hline & Use context & 2.95 & 2.71 & 2.00 & 1.41 \\
\hline & Technical testing & 3.21 & 1.86 & 1.95 & 2.88 \\
\hline & Long-term duration & 3.11 & 3.50 & 3.95 & 3.81 \\
\hline & Sample $N=64$ & 19 & 7 & 21 & 17 \\
\hline
\end{tabular}

Table 2: Characteristics and Descriptions of Living Lab Clusters

Within cluster 3, the largest cluster in our sample, we can discover some of the elements from the testbed-like Living Labs from our typology. User involvement is moderate, but runs over a long time period and with the largest user sample in comparison to the other clusters. Through a technological testbed-like infrastructure, a large user sample can be involved in co-creation and testing of ICT-services. An example for this third type is Botnia Living Lab (http://www.testplats.com) where more than 6.000 (potential) test users are available to try out innovative applications and services. Already more than 100 cases have taken place. For this third cluster, we can conclude that it is clearly provider-driven in terms of the infrastructure (testusers and networks), but is mainly utilizer-driven in the case of concrete projects. The final cluster, consisting of 17 Living Labs, is very similar to the American Living Labs from our typology. In a laboratory context with some familiarity in term of usage context, user behaviour is observed and recorded, with less focus on co-creation. As an example, we can mention the SMEDL Living Lab (http://www.socialmedia-nrw.de/). This Living Lab, aimed at exploring and dedeloping innovative home entertainment technologies, includes a stationary controlled testbed designed like a living room where all activity is logged and recorded [Hess \& Ogonowski, 2010]. Because of the heavy infrastructural component, these American Living Labs are mostly active for a longer time period, but only allowing smaller user samples to be involved.

\section{Conclusion}

Within this paper, we have proposed a fourfold typology of Living Labs based on the existing Living Labs literature. By means of an empirical assessment of 64 ICT-Living Labs from the 
ENoLL-community, we found a four cluster solution that more or less confirmed this typology. The four general Living Lab-types as they appear in literature and practice are American Living Labs, testbed-like Living Labs, Living Labs focused on intense user co-creation and Living Labs mainly as facilitators for multi-stakeholder collaboration and knowledge sharing. In terms of the driver of these Living Labs, we found that utilizer-driven and provider-driven Living Labs seem to be the most common, while enabler-driven seemed to be less common. Interestingly, userdriven Living Labs were not explicitly discovered or mentioned in the analysed literature. The Living Labs focussed on collaboration and knowledge sharing can be seen as divergent from the other three Living Labs in terms of initial focus, as they tend to focus on the network of Living Lab stakeholders and the effects of the network. The user, or rather a user community, is merely one of the stakeholders, whereas the other three emphasize user involvement and co-creation as central tenets of the Living Lab. These three Living Labs differ mostly in terms of size, duration and usage context, which can be 'real-world' or in a lab made to resemble the real world.

When looking at the stakeholder that drives the Living Lab, it became apparent that this differs according to the type and goal of the Living Lab. For the testbed-like Living Labs and for the American Living Labs, a distinction can be made between an infrastructural component and the concrete innovation cases that are run in the Living Lab. In terms of actors driving the Living $\mathrm{Lab}$, the infrastructural component is provider-driven, whereas the concrete cases and projects are mainly utilizer-driven.

Future research might go deeper into detail into this distinction. More studies regarding the nature and appearance of the various types of Living Labs is still needed. We now started from nine general characteristics, but further variables should be included in order to deepen the understanding and to allow to paint a more fine-grained picture of the current Living Labs movement. More insights are still needed in order to realize the full potential of the Living Labs movement.

\section{Acknowledgement}

The empirical research amongst the ENoLL-community has been carried out with kind permission of the ENoLL secretary. The authors wish to thank Anna Kivilehto, Alisa Kox and all participating Living Lab representatives for their time and effort dedicated to this research project.

\section{References}

Ballon, P., J. Pierson, et al. (2007). Fostering Innovation in Networked Communications: Test and Experimentation Platforms for Broadband Systems. Designing for Networked Communications: Strategies and Development. S. a. J. Heilesen. London, ISI Global: 137-166.

Buitendag, A. A., van der Walt, J. S., Malebane, T., \& de Jager, L. (2012). Addressing Knowledge Support Services as Part of a Living Lab Environment. Issues in Informing Science \& Information Technology, Volume 9 (2012), 9, 221.

Coetzee, H., Du Toit, I. M., \& Herselman, M. (2012). Living Labs in South Africa: An analysis based on five case studies. The Electronic Journal for Virtual Organizations and Networks, (14) August.

ENoLL (2012). The European Network of Living Labs - the first steps towards a new innovation system. Retrieved from the World Wide Web on November 19th, 2011: http://www.openlivinglabs.eu/livinglabs

Eriksson, M., Niitamo, V., Kulkki, S., (2005), "State-of-the-art in utilizing Living Labs approach to user-centric ICT innovation - a European approach". http://www.vinnova.se/upload/dokument/Verksamhet/TITA/Stateoftheart_LivingLabs_Eriksson2005.pdf

Følstad, A. (2008). "Living Labs for Innovation and Development of Communication Technology: A Literature Review." The Electronic Journal for Virtual Organisations and Networks 10: 99-131.

Hendri Coetzee, Ina-Mari du Toit \& Marlien Herselman. 2012. Living Labs in South Africa: an analysis based on five case studies. The Electronic Journal for Virtual Organizations and Networks, Volume 14, August 2012. 
Hess, J., \& Ogonowski, C. (2010). Steps toward a living lab for socialmedia concept evaluation and continuous user-involvement. In Proceedings of the 8th international interactive conference on Interactive TV\&Video (pp. 171-174). ACM.

Intille, S., Larson, K., (2005), “A living laboratory for the design and evaluation of ubiquitous computing technologies". Proceedings of CHI 2005: 1941-1944.

Leminen, S., M. Westerlund, and A-G.Nyström. (2012). Living Labs as Open-Innovation Networks. Technology Innovation Management Review. September 2012: 6-11.

Markopoulos, P., and Rauterberg, M., (2000) Living Lab - A White Paper, IPO - Annual Progress Report, 35.

Peltomäki, A., (2008), "Foreword. In Living Labs for user-driven open innovation: an overview of the Living Labs methodology, activities and achievements." European Commission, Luxembourg, Office for Official Publications of the European Communities 5.

Pierson, J. and B. Lievens (2005). Configuring Living Labs for a 'thick' Understanding of Innovation. EPIC Conference 2005.

Ponce de Leon, M., Eriksson, M., Balasubramaniam, S., \& Donnelly, W. (2006, March). Creating a distributed mobile networking testbed environment-through the living labs approach. In Testbeds and Research Infrastructures for the Development of Networks and Communities, 2006. TRIDENTCOM 2006. 2nd International Conference on (pp. 5-pp). IEEE.

Prime Minister's Office (2006a). European Network of Living Labs places people at the very centre of product development and innovation. Retrieved from the World Wide Web on March 21st, 2012: http://www.vnk.fi/ajankohtaista/tiedotteet/tiedote/fi.jsp?oid=175010\&c=0\&toid=5299\&moid=5301

Prime Minister's Office (2006b). The launch of a European Network of Living Labs - Co-creation of innovation in public, private and civic partnership. Retrieved from the World Wide Web on March 21st, 2012: http://vnk.fi/ajankohtaista/tiedotteet/tiedote/en.jsp?oid=149029

Santoro, R. \& Conte, M. (2009). Living Labs in Open Innovation Functional Regions. Proceedings of the 15th International Conference on Concurrent Engineering (ICE 2009), Leiden, The Netherlands, 22-24 June 2009.

Schaffers, H., Kulkki, S., (2007), "Living labs, An Open Innovation concept fostering rural development". AsiaPacific Tech Monitor (September).

Schuurman, D., De Moor, K., De Marez, L., \& Evens, T. (2011). A Living Lab research approach for mobile TV. Telematics and Informatics, 28(4), 271-282.Schuurman, D and L. De Marez (2012). Structuring User Involvement in Panel-Based Living Labs. Technology Innovation Management Review. September 2012: 3138.

Schuurman, D., \& De Marez, L. (2012). Structuring user involvement in panel-based Living Labs. Technology Innovation Management Review, (September 2012: Living Labs).

Shamsi, T. A. (2008). Living Labs: Good Practices in Europe. European Living Labs - A new approach for human centric regional innovation. J. Schumacher and V. Niitamo. Berlin, WVB: 15-30.

Ståhlbröst, A., Bergvall-Kåreborn, B., (2008), "FormIT - an Approach to User Involvement”. European Living Labs - A new approach for human centric regional innovation. Berlin, WVB: 64-75.

Steenkamp, J.-B.E.M., Hofstede, F.T. \& Wedel, M. (1999). A cross-national investigation into the individual and national cultural antecedents of consumer innovativeness". Journal of Marketing, Vol. 63(2): 55 - 69

Thiesen Winthereik, J., Malmborg, L., \& Andersen, T. (2009). Living Labs as a Methodological Approach to Universal Access in Senior Design. Universal Access in Human-Computer Interaction. Addressing Diversity, 174-183.

Zhong, X., Chan, H. H., Rogers, T. J., Rosenberg, C. P., \& Coyle, E. J. (2006, March). The development and eStadium testbeds for research and development of wireless services for large-scale sports venues. In Testbeds and Research Infrastructures for the Development of Networks and Communities, 2006. TRIDENTCOM 2006. 2nd International Conference on (pp. 9-pp). IEEE. 


\section{Annex - Codebook}

\section{CRITERION 1: Investigation of the usage context}

In order to give a high coding to this variable, the Living Lab should encompass methods that allow getting insights into the context of use, as well as the environment and the users' skills. It is critical for this criterion that these insights relate to the context in which insights are generated, and how the characteristics of the context may influence the findings; rather than seeing the Living Lab only as a random environment, in which a solution is presented to a user.

1: The usage context is not considered at all.

2: The usage context is a little bit considered; e.g. a simple survey at the end of the Living Lab may include questions that deal with the usage context

3: The usage context is substantially considered; e.g. the use of some advanced techniques that consider the context (see point 4); e.g. the adaptation of the environment to assess its impact on usage

4: The usage context is considered as a critical element that influences the usage behavior and actively managed by the partners being involved in the Living Lab; e.g. use of observational, ethnographic research, researchers assess the usage context (i.e. context analysis)

\section{CRITERION 3: Co-creation with the user}

Co-creation implies a continuous process of feedback and adaption between (some of) the users and the organizations involved in the Living Lab as the developers of the innovation. Co-creation implies an intellectual effort of these users in the shaping of the innovation and to provide users with possibilities to alter/adapt a new product/service. This criterion is rated, depending on the degree of involvement and the actual utilization of user feedback and suggestions for the (re-)shaping of the innovation.

1: There is no interaction between researchers and users for improving the product/service.

2: User suggestions for modifications/alterations are somewhat captured (e.g. by a survey), but not in an iterative manner. 3: Opportunities for modifications/alterations are given and captured, which may lead to modifications/alterations and then the innovation is presented again to the users (iterative process). 4: Users can actively contribute to the alteration/modification, by giving solution information or even by making changes themselves (active user input, iteration). The users are clearly a part of the innovation process.

\section{CRITERION 5: Technical testing of the innovation in a realistic} context

This criterion implies that within the Living Lab some kind of assessment of the technical aspects of the innovation is made. This does not necessarily imply user feedback, but it is rather done by experts or with the help of specialized equipment.

1: No technical testing is present.

2: Technical performance is simply monitored during usage. 3: Technical performance is monitored during usage and also while users are not using the innovation, in order to get some technical testing results.

4: Technical performance is monitored thoroughly and 'extreme' usage or use cases are invoked, in order to test the technical performance of the innovation.
CRITERION 2: Discover unexpected (ICT-)uses and new service

opportunities

This criterion is rated as high, if the applied research methods and techniques allow capturing alternative, unforeseen and unexpected behavior and usage patterns, according to the innovation. Discovery relates to the early stages of the innovation process such as need analysis or idea generation.

1: There are no opportunities to capture unexpected usage or new opportunities.

2: The Living Lab-setting allows to some extent to discover unforeseen usage patterns and unexpected behavior e.g., a simple survey at the end of the Living Lab that looks for unexpected uses and/or opportunities generated by respondents; very new ideas of users that may emerge can be captured

3: The Living Lab includes research in the early stage of the innovation, e.g. through idea generation for new services or a simple need analysis

4: Systematic and thorough inclusion of methods that focus on the early stages of the innovation process, e.g. users' needs analysis, idea generation through idea box or focus group workshop, confronting users with very early prototypes to provoke reactions (rather than prototype testing close to new product/service launch). Researchers actively engage in looking for unexpected usage (e.g. by observing the users) and new opportunities

\section{CRITERION 4: Evaluation of new (ICT-)solutions by user}

This criterion is evaluated as being high, if the innovation is evaluated in any way by the users. This feedback can be given during the usage or after the usage by means of different research methods or techniques. This implies that the users are able to give some kind of rating to the innovation, either positively or negatively, and to validate new solutions

1: There is no evaluation by the users.

2: There is a brief evaluation of the innovation; e.g. by post-usage survey

3: More thorough evaluation of the innovation is given post-usage; e.g. through a more interactive research method like for example focus groups

4: Multiple possibilities of feedback and evaluation by users during usage, and possibly also post-usage, are given.

\section{CRITERION 6: Familiar usage context for the users}

This criterion can be rated high, if the innovation can be tested and used in a context that is familiar to the users and that resembles or coincides with the eventual intended usage context. With this criterion, Living Labs differentiate themselves from artificial laboratory settings. The focus lays on the users' familiarity with the context, and not necessarily the realistic attributes of the context. 1: A laboratory setting. Ecological validity is clearly threatened. 2: A laboratory setting with some elements that imitate a familiar usage context for the users.

3: A laboratory setting that tries to recreate a familiar usage context as much as possible.

4: A realistic setting that reflects the users' natural environment. 
CRITERION 7: Experience and experiment in a real-world context This criterion means that the innovation is tested and used in a real-world context, so beyond the laboratory setting. Limitations of the use in a real-world context might be of geographical nature, related to users' skills (because they require completely new skills and expertise) or related to users that are not involved in the Living Lab (e.g. because non-included users would need special devices to communicate with the Living Lab users).

1: A laboratory setting.

2: A real-world context with severe limitations on time and/or space, where the innovation can be used.

3: A real-world context with some limitations on time and/or space where the innovation can be used

4: A real-world context without any limitations.

\section{CRITERION 8: Medium- or long-term user studies}

This criterion speaks for itself. When longitudinal user studies are present i.e. studies that are carried out over a prolonged period of time, this criterion can be given a high score. The exact duration of the Living Lab (not of a single innovation!) will be used as a

measure. E.g. 1: one time trial of an innovation to 4: over months

\section{CRITERION 9: Large scale user studies}

As with the previous one, this last criterion is also quite straight forward in wording. The assessment relates to the number of users involved. As it can be argued that the scale of the user studies is relative to the type of innovation being tested and/or co-created in the Living Lab (and other criteria), this variable simply registers how many users participated in the Living Lab. 